\title{
Role of L-alanine for redox self-sufficient amination of alcohols
}

Stephanie Klatte and Volker F Wendisch ${ }^{*}$

\begin{abstract}
Background: In white biotechnology biocatalysis represents a key technology for chemical functionalization of non-natural compounds. The plasmid-born overproduction of an alcohol dehydrogenase, an L-alanine-dependent transaminase and an alanine dehydrogenase allows for redox self-sufficient amination of alcohols in whole cell biotransformation. Here, conditions to optimize the whole cell biocatalyst presented in (Bioorg Med Chem 22:5578-5585, 2014), and the role of L-alanine for efficient amine functionalization of 1,10-decanediol to 1,10-diaminodecane were analyzed.
\end{abstract}

Results: The enzymes of the cascade for amine functionalization of alcohols were characterized in vitro to find optimal conditions for an efficient process. Transaminase from Chromobacterium violaceum, Ta $\mathrm{C}_{\mathrm{C},}$, showed three-fold higher catalytic efficiency than transaminase from Vibrio fluvialis, Tavf, and improved production at $37^{\circ} \mathrm{C}$. At $42^{\circ} \mathrm{C}$, $\mathrm{Ta}_{\mathrm{Cr}}$ was more active, which matched thermostable alcohol dehydrogenase and alanine dehydrogenase and improved the 1,10-diaminodecane production rate four-fold. To study the role of $\mathrm{L}$-alanine in the whole cell biotransformation, the L-alanine concentration was varied and 1,10.diaminodecane formation tested with constant $10 \mathrm{mM}$ 1,10- decanediol and $100 \mathrm{mM} \mathrm{NH}_{4} \mathrm{Cl}$. Only 5.6\% diamine product were observed without added L-alanine. L-alanine concentrations equimolar to that of the alcohol enabled for $94 \%$ product formation but higher $L$-alanine concentrations allowed for $100 \%$ product formation. L-alanine was consumed by the E. coli biocatalyst, presumably due to pyruvate catabolism since up to $16 \mathrm{mM}$ acetate accumulated. Biotransformation employing E. coli strain YYC202/pTrc99a-ald-adh-ta ${ }_{\mathrm{Cv}}$ which is unable to catabolize pyruvate, resulted in conversion with a selectivity of 42 mol-\%. Biotransformation with E. coli strains only lacking pyruvate oxidase PoxB showed similar reduced amination of 1,10-decanediol indicating that oxidative decarboxylation of pyruvate to acetate by PoxB is primarily responsible for pyruvate catabolism during redox self-sufficient amination of alcohols using this whole cell biocatalyst.

Conclusion: The replacement of the transaminase $\operatorname{Ta}_{\mathrm{vf}}$ by $\mathrm{Ta}_{\mathrm{Cv}}$, which showed higher activity at $42^{\circ} \mathrm{C}$, in the artificial operon ald-adh-ta improved amination of alcohols in whole cell biotransformation. The addition of L-alanine, which was consumed by E. coli via pyruvate catabolism, was required for $100 \%$ product formation possibly by providing maintenance energy. Metabolic engineering revealed that pyruvate catabolism occurred primarily via oxidative decarboxylation to acetate by PoxB under the chosen biotranformation conditions.

Keywords: Redox self-sufficient amination, Whole cell biotransformation, Escherichia coli, Transaminase, Chromobacterium violaceum, Energy maintenance, Acetate formation, Pyruvate oxidase, Phosphate acetyltransferase, Acetate kinase

\footnotetext{
* Correspondence: volker.wendisch@uni-bielefeld.de

Chair of Genetics of Prokaryotes, Faculty of Biology \& CeBiTec, Bielefeld

University, Universitaetsstr. 25, 33615 Bielefeld, Germany
}

\section{Biomed Central}

(c) 2015 Klatte and Wendisch; licensee BioMed Central. This is an Open Access article distributed under the terms of the Creative Commons Attribution License (http://creativecommons.org/licenses/by/4.0), which permits unrestricted use, distribution, and reproduction in any medium, provided the original work is properly credited. The Creative Commons Public Domain Dedication waiver (http://creativecommons.org/publicdomain/zero/1.0/) applies to the data made available in this article, unless otherwise stated. 


\section{Background}

White biotechnology is the key technology for alternative and sustainable production of e.g. fine chemicals. Its application in biocatalysis is considered a branch of Green Chemistry which can replace or complement routes of chemical modification and functionalization. Enzymes catalyze reactions under mild conditions contrarily to chemical catalysts which often demands high pressure and temperature as well as toxic solvents. Among others, amine functionalization of chemical compounds is an important approach in biocatalysis to produce (poly)amines which are components of for example synthetics and coatings. This can be performed by amino acid dehydrogenases catalyzing NADH-dependent reductive amination of oxo-acids with ammonium or by transaminases transferring an amino group from a donor amine to a carbonyl compound. The cofactor pyridoxal-phosphate is covalently bound to the catalytic center of $\omega$-transaminases to transfer the amino group to the acceptor molecule [1,2].

Generally, in biocatalysis the use of a transaminase instead of an amino-acid dehydrogenase offers the access to a wider range of substrates since amino-acid dehydrogenases accept a restricted spectrum of $\alpha$-keto acids. Coupling of both types of enzymes enables amine functionalization of a wider range of carbonyl compounds from ammonium in a redox dependent manner. Therefore, redox cofactor recycling is important to reduce the process costs. Cofactor recycling by cascading with, for example, glucose dehydrogenase or formate dehydrogenase or for whole cell biocatalysts with cellular glucose catabolism have been developed [3,4]. A three enzyme cascade for recycling redox cofactor and amino group donor has been demonstrated in cell free biocatalysis using an alanine dehydrogenase coupled with a L-alanine-dependent transaminase and an alcohol dehydrogenase [5]. The initial alcohol oxidation by an alcohol dehydrogenase yields $\mathrm{NADH}$ and the aldehyde which is converted to the amine by L-alanine-dependent transamination (Figure 1A). Alanine dehydrogenase recycles L-alanine using ammonium and NADH releasing $\mathrm{NAD}^{+}$as redox cofactor for the alcohol dehydrogenase. Recently, this concept of redox selfsufficient amination of alcohols (Figure 1A) was realized in a whole cell process with Escherichia coli by plasmidborn overproduction of the alcohol dehydrogenase of Bacillus stearothermophilus, the transaminase of Vibrio fluvialis and the alanine dehydrogenase of Bacillus subtilis [6]. Advantageously, the whole cell process only required alcohol, L-alanine and ammonium but neither NAD nor PLP. In principle, L-alanine addition is not required in the three-enzyme-cascade and amination of alcohols to amines should be possible with an ammonium salt. However, whole cells require energy to maintain viability as well as for transport processes e.g. substrate uptake and product export as well as protein synthesis under starvation or other stress conditions. Since non-growing cells are typically used for whole cell biotransformation, the nongrowth-associated maintenance coefficient reflects the cell's requirement to catabolize an energy substrate such as glucose to keep the cell's viability and functionality. Therefore, the role of L-alanine in the whole cell biotransformation of alcohols to amines was analysed and conditions for optimizing the whole cell biocatalyst towards improved amino functionalization of alcohols were tested.

\section{Results}

\section{Construction of the whole cell biocatalyst W3110/ pTrc99A-ald-adh-ta $a_{\mathrm{Cv}}$ and its comparison to W3110/ pTrc99A-ald-adh-ta $a_{\mathrm{vf}}$ in vitro and in vivo}

The whole cell biocatalyst W3110/pTrc99A-ald-adh-ta $a_{\mathrm{Vf}}$ was previously shown to enable redox self-sufficient amination of a variety of alcohols [6] and involved thermo-sensitive transaminase from Vibrio fluvialis. Due to the thermostable alcohol dehydrogenase of $B$. stearothermophilus an increased reaction temperature for redox self-sufficient amination was considered to improve the production rate. Therefore, the gene for the transaminase of $V$. fluvialis was replaced by the gene for the transaminase of $C$. violaceum in the IPTG-inducible vector pTrc99Aald-adh-ta $a_{\mathrm{V} f}$. The vector was used to transform $E$. coli W3110 to yield the whole cell biocatalyst W3110/pTrc99Aald-adh- $t a_{\mathrm{Cr}}$. Enzyme activity assays of the newly constructed whole cell biocatalyst revealed that all three genes were functionally expressed. The crude extracts displayed enzyme activities of $9.8 \pm 1.1$ and $0.55 \pm 0.03 \mathrm{U} / \mathrm{mg}$ for the alanine dehydrogenase and the alcohol dehydrogenase, respectively, which was similar to the activities in W3110/pTrc99a-ald-

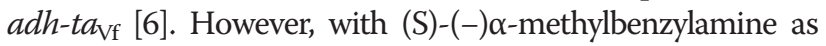
substrate, the specific activities of transaminase $\mathrm{Ta}_{\mathrm{Cv}}$ of $0.62 \pm$ 0.01 in W3110/pTrc99a-ald-adh-ta $a_{\mathrm{Cv}}$ were two-fold higher than that of $\mathrm{Ta}_{\mathrm{Vf}}$ in W3110/pTrc99a-ald-adh-ta $a_{\mathrm{VF}}$.

The catalytic efficiencies of both transaminases were estimated with L-alanine as donor substrate and hexanal as acceptor substrate. Therefore, crude extracts of W3110/ pTrc99a- $t a_{\mathrm{Vf}}$ and W3110/pTrc99a- $t a_{\mathrm{Cv}}$ were assayed in a $50 \mathrm{mM}$ potassium-phosphate buffer $\mathrm{pH}$ 7.4 with constant hexanal and varying $\mathrm{L}$-alanine concentrations at $37^{\circ} \mathrm{C}$. The $\mathrm{L}$-alanine-dependent transamination of hexanal to hexylamine could be detected for both transaminases and $\mathrm{K}_{\mathrm{m}}{ }^{-}$ and $\mathrm{V}_{\max }$-values for $\mathrm{Ta}_{\mathrm{Vf}}$ were $20 \mathrm{mM} \mathrm{L}$-alanine and 0.3 $\mathrm{U} / \mathrm{mg}$, respectively, and $35 \mathrm{mM} \mathrm{L}$-alanine and $2 \mathrm{U} / \mathrm{mg}$, respectively, for $\mathrm{Ta}_{\mathrm{Cv}}$ (Table 1). The catalytic efficiency reflected by the $\mathrm{V}_{\max } / \mathrm{K}_{\mathrm{m}}$-value was 3-fold higher for $\mathrm{Ta}_{\mathrm{Cv}}$ than for $\operatorname{Tavf}_{\mathrm{vf}}\left(0.06\right.$ compared to $\left.0.02 \mathrm{U} \mathrm{mg}^{-1} \mathrm{mM}^{-1}\right)$.

To compare the whole cell biocatalysts W3110/pTrc99Aald-adh- $t a_{\mathrm{Cv}}$ and W3110/pTrc99A-ald-adh-ta $a_{\mathrm{Vf}}$ for the redox-self-sufficient amination of alcohols conversion of the diol 1,10-decanediol was tested. The addition of 1,10-decanediol, $100 \mathrm{mM} \mathrm{L}$-alanine and $100 \mathrm{mM}$ 


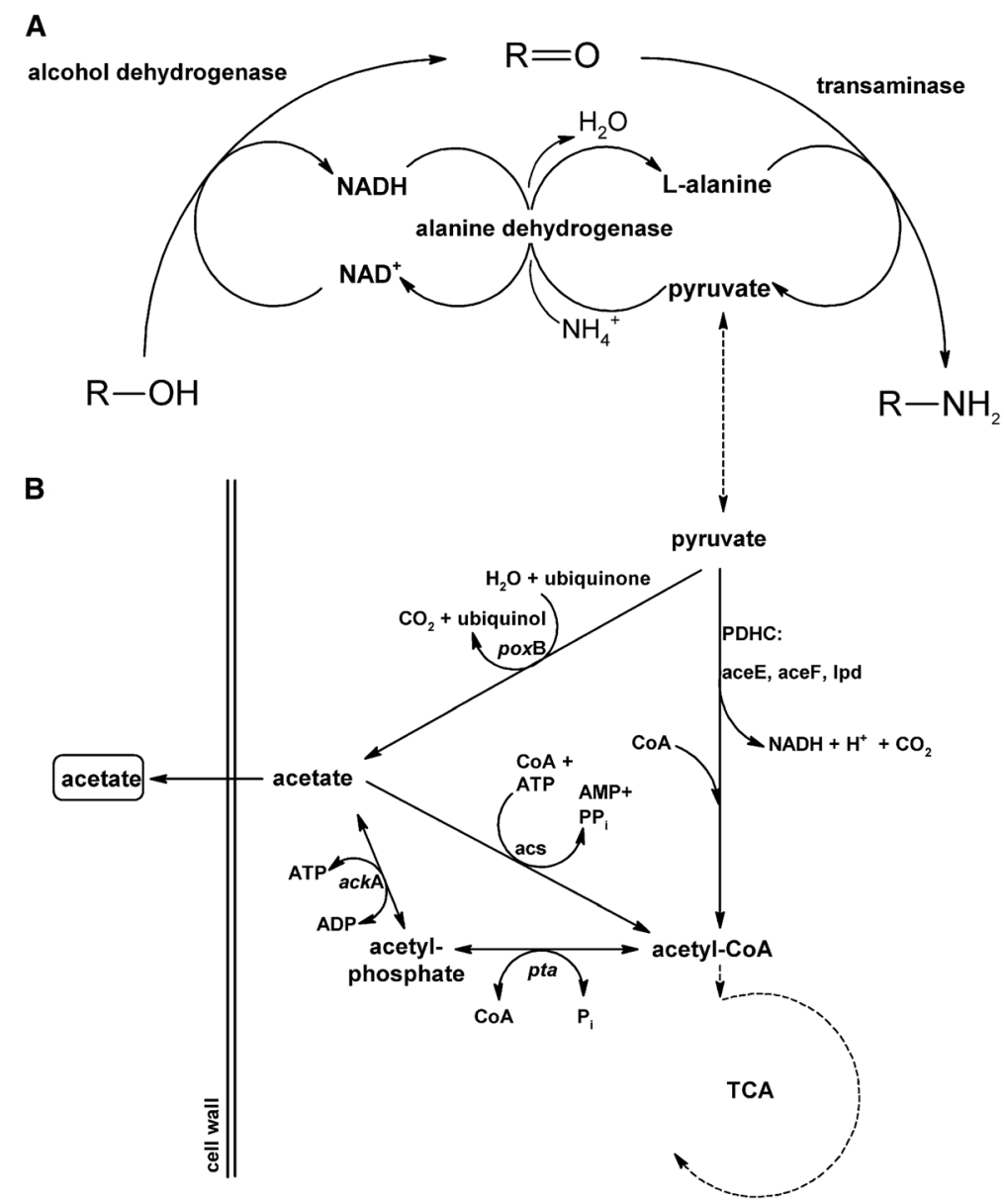

Figure 1 Redox self-sufficient amination by coupling an alcohol dehydrogenase, L-alanine-dependent transaminase and L-alanine dehydrogenase (A); Catabolic reactions of Escherichia coli converting pyruvate (B). For the reactions depicted in (B) gene names of pyruvate oxidase (poxB), the pyruvate dehydrogenase complex (aceEFlpd), acetyl-CoA synthetase (acs), phosphotransacetylase (pta) and acetate kinase (ackA) are given.

$\mathrm{NH}_{4} \mathrm{Cl}$ resulted in $100 \%$ product formation employing the newly derived catalyst W3110/pTrc99a-ald-adh-ta $a_{\mathrm{Cv}}$ (Table 2) as well as employing the previously designed W3110/pTrc99a-ald-adh-ta $a_{\mathrm{Vf}}[6]$. When the L-alanine concentration was reduced to $50 \mathrm{mM}$ or $20 \mathrm{mM}$, production of 1,10-diaminodecane using W3110/pTrc99a-ald$a d h-t a_{\mathrm{CV}}$ and W3110/pTrc99a-ald-adh- $t a_{\mathrm{Vf}}$ was reduced to $84 \%$ and $86 \%$, respectively, and $73 \%$ and $50 \%$, respectively (Table 2). HPLC analysis revealed that both strains consumed between 16 and $30 \mathrm{mM} \mathrm{L}$-alanine (Table 2). Taken together, the newly constructed biocatalyst W3110/

Table 1 In vitro estimation of the catalytic efficiencies of transaminases $\mathrm{Ta}_{\mathrm{Vf}}$ and $\mathrm{Ta}_{\mathrm{Cv}}$ with L-alanine and hexanal as substrates

\begin{tabular}{llll}
\hline $\begin{array}{l}\text { Origin of the } \\
\text { transaminase }\end{array}$ & $\mathrm{K}_{\mathbf{m}}$ for L-alanine $[\mathrm{mM}]$ & $\mathbf{V}_{\max }[\mathbf{U} / \mathbf{m g}]$ & $\mathbf{V}_{\mathbf{m a x}} / \mathbf{K}_{\mathbf{m}}$ \\
\hline V. fluvialis & $20.00 \pm 1.10$ & $0.30 \pm 0.01$ & 0.02 \\
C. violaceum & $35.00 \pm 2.20$ & $2.00 \pm 0.07$ & 0.06 \\
\hline
\end{tabular}

pTrc99a-ald-adh- $t a_{\mathrm{Cv}}$ showed higher activity and catalytic efficiency with respect to the transaminase and higher selectivity at $37^{\circ} \mathrm{C}$ and with low $\mathrm{L}$-alanine concentrations.

Influence of the reaction temperature on amination of 1,10-decanediol to 1,10-diaminodecane by W3110/ pTrc99a-ald-adh-ta $a_{\mathrm{Vf}}$ and W3110/pTrc99a-ald-adh-ta $a_{\mathrm{CV}}$ The three-enzyme-cascade contains thermostable alcohol dehydrogenase from the thermophilic B. stearothermophilus, but little is known about the activity of the alanine dehydrogenase from $B$. subtilis and the two transaminases of $V$. fluvialis and C. violaceum at higher temperatures. The activities of all enzymes were analyzed at varying temperatures in crude extracts of W3110/pTrc99a-adh, W3110/ pTrc99A-ald, W3110/pTrc99a-ta $a_{\mathrm{Vf}}$ as well as W3110/ pTrc99a- $t a_{\mathrm{Cv}}$. For the alanine dehydrogenase of B. subtilis and the alcohol dehydrogenase of $B$. stearothermophilus, enzyme activities increased with temperature ranging from $30^{\circ} \mathrm{C}$ to $60^{\circ} \mathrm{C}$ and $20 \mathrm{U} / \mathrm{mg}$ and $1.8 \mathrm{U} / \mathrm{mg}$, respectively, with maxima at about $60^{\circ} \mathrm{C}$ (Figure 2). The activity of the 
Table 2 Comparison of the redox self-sufficent amination of 1,10-decanediol by W3110/pTrc99a-ald-adh-ta $a_{\mathrm{Vf}}$ and W3110/pTrc99a-ald-adh-ta $a_{\mathrm{Cv}}$ with varying L-alanine concentrations

\begin{tabular}{|c|c|c|c|c|}
\hline Strain & Biotransformation conditions & Reaction temperature $\left[{ }^{\circ} \mathrm{C}\right]$ & Max. conversion [\%] & Alanine consumption [mM] \\
\hline \multirow[t]{3}{*}{ W3110/pTrc99a-ald-adh-ta $a_{\mathrm{Cv}}$} & $100 \mathrm{mM}$ alanine, $100 \mathrm{mM} \mathrm{NH}_{4} \mathrm{Cl}$ & 37 & $100_{12 h}$ & 30 \\
\hline & $50 \mathrm{mM}$ alanine, $100 \mathrm{mM} \mathrm{NH}_{4} \mathrm{Cl}$ & & $84_{12 \mathrm{~h}}$ & 30 \\
\hline & $20 \mathrm{mM}$ alanine, $100 \mathrm{mM} \mathrm{NH}_{4} \mathrm{Cl}$ & & $86_{8 h}$ & 16 \\
\hline \multirow[t]{3}{*}{ W3110/pTrc99a-ald-adh-ta $a_{\mathrm{Vf}}$} & $100 \mathrm{mM}$ alanine, $100 \mathrm{mM} \mathrm{NH}_{4} \mathrm{Cl}$ & 37 & $100_{24 h}$ & 30 \\
\hline & $50 \mathrm{mM}$ alanine, $100 \mathrm{mM} \mathrm{NH}_{4} \mathrm{Cl}$ & & $73_{12 \mathrm{~h}}$ & 26 \\
\hline & $20 \mathrm{mM}$ alanine, $100 \mathrm{mM} \mathrm{NH}_{4} \mathrm{Cl}$ & & $50_{12 \mathrm{~h}}$ & 18 \\
\hline
\end{tabular}

transaminase of $V$. fluvialis $\left(\mathrm{Ta}_{\mathrm{Vf}}\right)$ in the crude extract of W3110/pTrc99a-ta $a_{\mathrm{Vf}}$ dropped from $0.5 \mathrm{U} / \mathrm{mg}$ to $0.03 \mathrm{U} / \mathrm{mg}$ when the reaction temperature increased from $37^{\circ} \mathrm{C}$ to $42^{\circ} \mathrm{C}$. The activity of transaminase of C. violaceum $\left(\mathrm{Ta}_{\mathrm{Cv}}\right)$ was also lower at $42^{\circ} \mathrm{C}(0.13 \mathrm{U} / \mathrm{mg})$ than at $37^{\circ} \mathrm{C}(0.66$

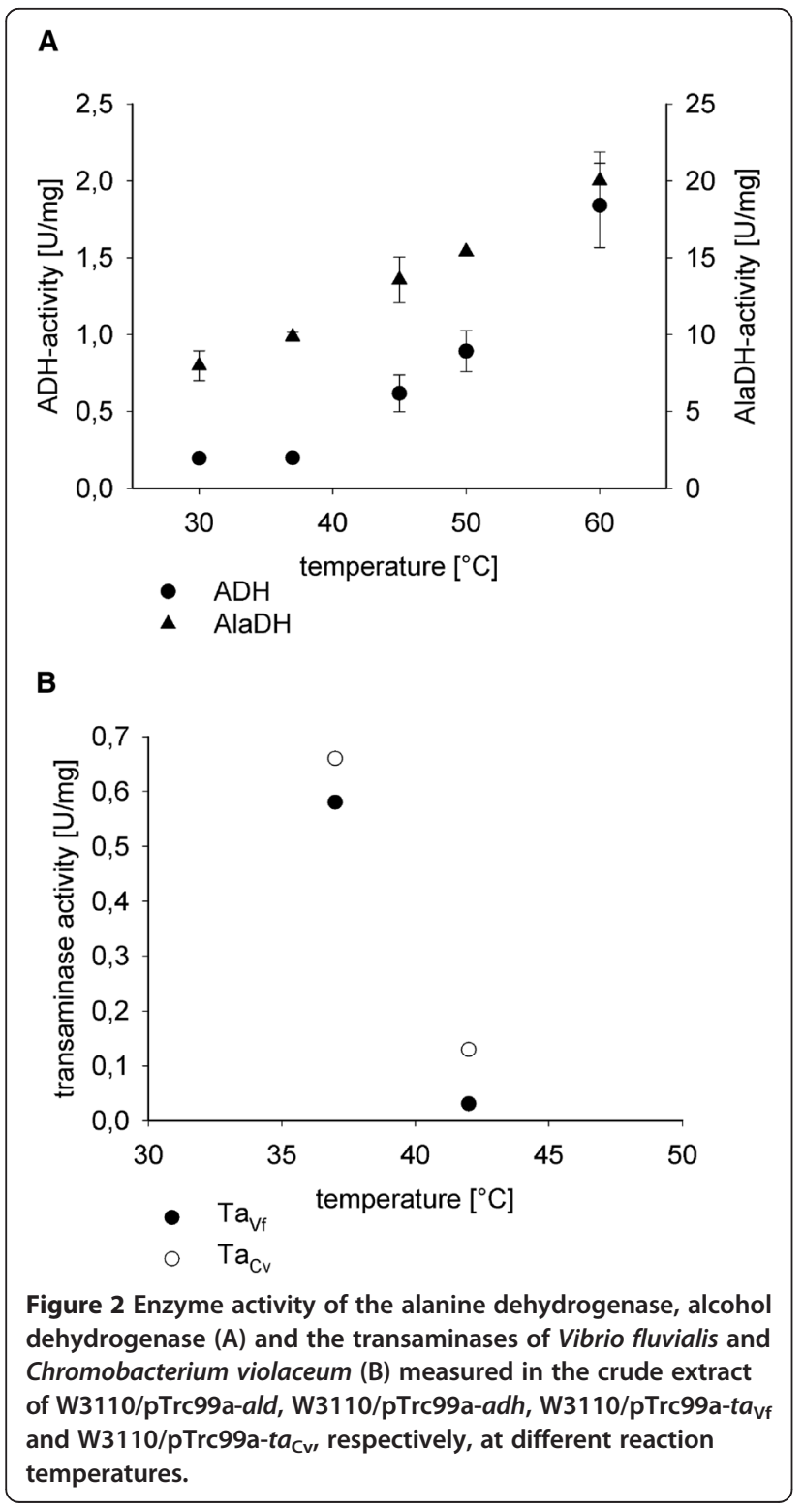

$\mathrm{U} / \mathrm{mg}$ ), but its activity at $42^{\circ} \mathrm{C}$ was four-fold higher than that of $\mathrm{Ta}_{\mathrm{Vf}}$ at $42^{\circ} \mathrm{C}$ (Figure 2).

To assay the influence of the reaction temperature on the amination cascade, whole cell biotransformations with W3110/pTrc99a-ald-adh-ta $a_{\mathrm{Vf}}$ and W3110/pTrc99a-aldadh-ta $a_{\mathrm{Cv}}$ were performed at $37^{\circ} \mathrm{C}, 40^{\circ} \mathrm{C}$ and $42^{\circ} \mathrm{C}$ being suitable temperatures for the host $E$. coli. 1,10-decanediol was chosen as a substrate since it was among the best substrates of this cascade [5,7] and, moreover, the use of this dialcohol allows for monitoring 1-amino-10decanol, an intermediate of diamine formation. The diamine production of both strains was compared in a resting buffer system using 1,10-decanediol as substrate, $100 \mathrm{mM} \mathrm{L}$-alanine and $100 \mathrm{mM} \mathrm{NH}_{4} \mathrm{Cl}$. In vivo amination of 1,10-decanediol performed by the two whole cell biocatalysts reached 100 mol- $\%$ selectivity after 24 hours at $37^{\circ} \mathrm{C}$ and production rates of about $0.06 \mathrm{~g} / \mathrm{g}^{*} \mathrm{~h}(0.35$ $\mathrm{mmole} / \mathrm{g}^{*} \mathrm{~h}$ ) were calculated (Figure 3 ). Furthermore, the increase of the reaction temperature from $37^{\circ} \mathrm{C}$ to $40^{\circ} \mathrm{C}$ and $42^{\circ} \mathrm{C}$ improved the production rates to $0.15 \mathrm{~g} / \mathrm{g} * \mathrm{~h}(0.87$ $\mathrm{mmole} / \mathrm{g} * \mathrm{~h})$ and $0.2 \mathrm{~g} / \mathrm{g} * \mathrm{~h}(1.16 \mathrm{mmole} / \mathrm{g}$ \% $\mathrm{h})$, respectively, when the newly constructed W3110/pTrc99a-ald-adh-ta $\mathrm{Cv}$ was employed. Contrarily, with W3110/pTrc99a-ald-adh$t a_{\mathrm{Vf}}$ substrate conversion to 1,10-diaminodecane (74\% and $56 \%$, respectively) and production rates $\left(0.04 \mathrm{~g} / \mathrm{g}^{*} \mathrm{~h}\right.$ and $0.03 \mathrm{~g} / \mathrm{g}^{*} \mathrm{~h}$, respectively) were lower at $40^{\circ} \mathrm{C}$ and $42^{\circ} \mathrm{C}$, respectively, as compared to $37^{\circ} \mathrm{C}$ (Figure 3). Thus, under the chosen conditions W3110/pTrc99a-ald-adh-ta $a_{\mathrm{Cv}}$ was superior to W3110/pTrc99a-ald-adh-tavf at an elevated temperature.

The role of L-alanine for the redox self-sufficient amination of alcohols in a whole cell process

L-alanine was a component of the hitherto described redox self-sufficient amination of alcohols with cascaded enzymes or as whole cell biotransformation $[5,6]$ as well as in the experiments described above to serve as amino group donor in L-alanine-dependent transamination. However, conceptually redox self-sufficient amination of alcohols does not require the addition of $\mathrm{L}$-alanine, but may proceed from ammonium only (Figure 1A). Thus, in order to find out if external addition of L-alanine is necessary to drive amination of 1,10-decanediol via this cascade, 


\begin{tabular}{c|ccc}
\multicolumn{4}{l}{ Product formation [\%] } \\
\hline transaminase & $\mathbf{3 7 ^ { \circ } \mathbf { C }}$ & $\mathbf{4 0}{ }^{\circ} \mathbf{C}$ & $\mathbf{4 2}^{\circ} \mathbf{C}$ \\
\hline $\mathrm{TA}_{\mathrm{Vf}}$ & 98 & 76 & 54 \\
$\mathrm{TA}_{\mathrm{CV}}$ & 100 & 100 & 100
\end{tabular}

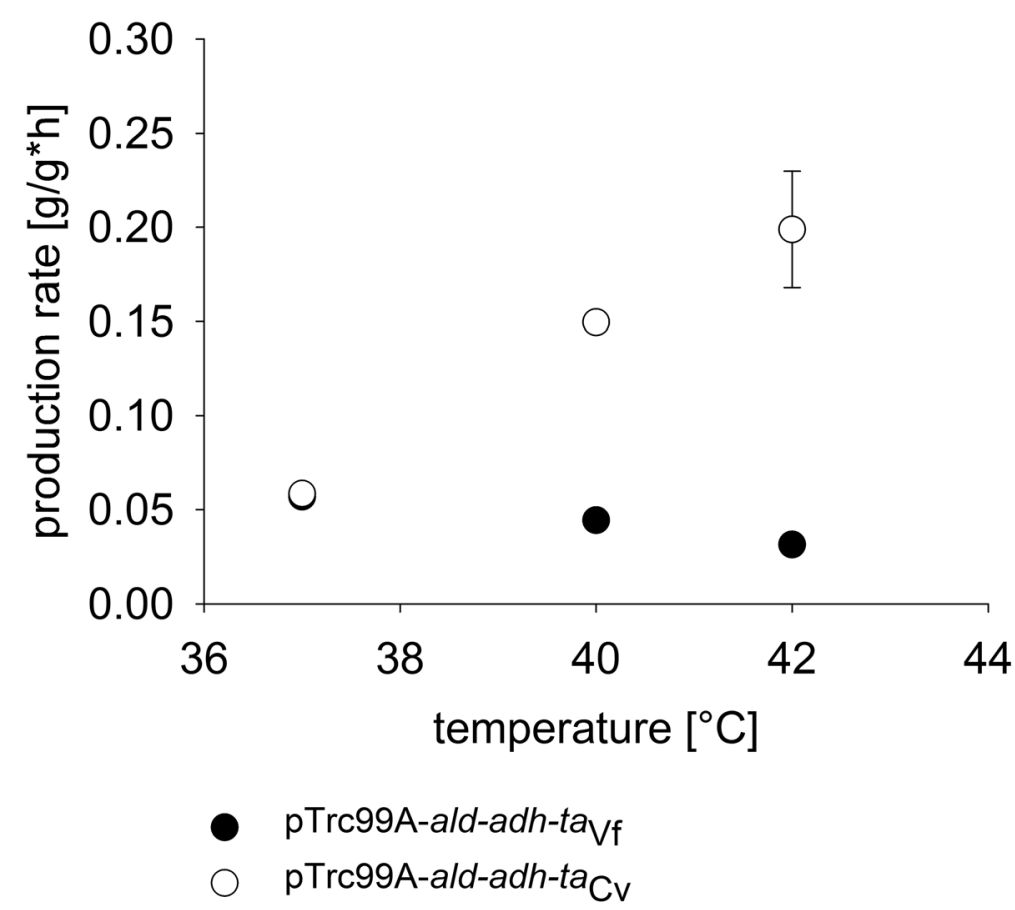

Figure 3 Comparison of the production rate and product formation for redox self-sufficient amination of 1,10 -decanediol at $37^{\circ} \mathrm{C}, 40^{\circ} \mathrm{C}$ and $42^{\circ} \mathrm{C}$ using whole cell biocatalysts W3110/pTrc99a-ald-adh-ta $\mathrm{vf}_{\mathrm{vf}}$ and W3110/pTrc99a-ald-adh-ta $\mathrm{Cv}_{\mathrm{Cv}}$. The cells were taken for whole cell biotransformation after 15 hours of gene expression in $\mathrm{LB}+20 \mathrm{mM}$ Mops at $37^{\circ} \mathrm{C}$. In a resting system consisting of $50 \mathrm{mM} \mathrm{Hepes} \mathrm{pH7,} 10 \mathrm{mM}$ 1,10-decanediol, $100 \mathrm{mM} \mathrm{L-alanine} \mathrm{and} 100 \mathrm{mM} \mathrm{NH}_{4} \mathrm{Cl}$ an optical density at $600 \mathrm{~nm}$ of 10 was adjusted.

varying L-alanine concentrations were assayed using biocatalyst W3110/pTrc99a-ald-adh-ta $a_{\mathrm{Cv}}$ at $42^{\circ} \mathrm{C}$ with a constant concentration of $100 \mathrm{mM} \mathrm{NH}_{4} \mathrm{Cl}$. At reduced L-alanine concentrations of $50 \mathrm{mM}$ and $20 \mathrm{mM}$ complete conversion of 1,10-decanediol to 1,10-diaminodecane was observed after 6 hours. With $10 \mathrm{mM}$ and $5 \mathrm{mM}$ L-alanine selectivity was almost complete $(94 \%$ and $93 \%$, respectively), whereas only $5.6 \%$ conversion of 1,10-decanediol to 1,10-diaminodecane was observed without adding L-alanine (Table 3 ). Thus, L-alanine has to be present for efficient amination of alcohols using biocatalyst W3110/pTrc99a-ald-adh-ta $a_{\mathrm{Cv}}$.

L-alanine added was utilized completely (at 5 and $10 \mathrm{mM}$ ) or partially (at 20 and $50 \mathrm{mM}$ ) during the whole cell biotransformation approach. Under certain conditions, acetate accumulated as by-product. When L-alanine was present at the same or lower concentrations as the substrate 1,10-decanediol, acetate accumulation was not observed, however, at higher L-alanine excess increasing
Table 3 Whole cell biotransformation with W3110/pTrc99aald-adh-ta $a_{\mathrm{Cv}}$ at $42^{\circ} \mathrm{C}$ with $100 \mathrm{mM} \mathrm{NH}_{4} \mathrm{Cl}$ and various L-alanine concentrations

\begin{tabular}{|c|c|c|c|c|}
\hline \multicolumn{2}{|c|}{ Biotransformation conditions } & \multirow{2}{*}{$\begin{array}{l}\text { Conversion } \\
\text { [\%] }\end{array}$} & \multirow{2}{*}{$\begin{array}{l}\text { L-alanine } \\
\text { consumption } \\
{[\mathrm{mM}]}\end{array}$} & \multirow{2}{*}{$\begin{array}{l}\text { Acetate } \\
\text { production } \\
{[\mathrm{mM}]}\end{array}$} \\
\hline 1,10-decanediol & L-alanine & & & \\
\hline $10 \mathrm{mM}$ & $50 \mathrm{mM}$ & $100_{6 h}$ & 23 & 16 \\
\hline $10 \mathrm{mM}$ & $20 \mathrm{mM}$ & $100_{6 h}$ & 13 & 3 \\
\hline $10 \mathrm{mM}$ & $10 \mathrm{mM}$ & $94_{12 h}$ & 10 & 0 \\
\hline $10 \mathrm{mM}$ & $5 \mathrm{mM}$ & $93_{12 \mathrm{~h}}$ & 5 & 0 \\
\hline $10 \mathrm{mM}$ & $0 \mathrm{mM}$ & $5,6_{8 h}$ & 0 & 0 \\
\hline $0 \mathrm{mM}$ & $20 \mathrm{mM}$ & $0_{12 h}$ & 20 & 2 \\
\hline $10 \mathrm{mM}$ & $\begin{array}{l}0 \mathrm{mM}+20 \mathrm{mM} \\
\text { pyruvate }\end{array}$ & $70_{4 h}$ & 7 & 7 \\
\hline
\end{tabular}


acetate concentrations could be observed (Table 3). Lalanine $(20 \mathrm{mM})$ was catabolized entirely in the absence of the substrate 1,10-decanediol. Pyruvate only partially replaced L-alanine since only $70 \%$ product formation were detected with $20 \mathrm{mM}$ pyruvate. Taken together, these results indicate L-alanine consumption and acetate formation by the host's central carbon metabolism.

To test if L-alanine consumption is important for the redox self-sufficient amination of alcohols with this whole cell biocatalyst or a dispensable side reaction, the host's pyruvate catabolism was blocked at various positions. $E$. coli YYC202 cannot catabolize pyruvate (Figure 1) since it lacks the pyruvate dehydrogenase complex (deletion of $a c e E F$ ), phosphoenyl pyruvate synthetase (mutation of $p p s$ ), pyruvate formate lyase $(p f l B)$ and pyruvate oxidase $(p o x B)$ [7]. Heterologous overexpression of ald, adh and $t a_{\mathrm{Cv}}$ in E. coli $\mathrm{YYC} 202$ led to $42 \%$ conversion of 1,10-decanediol to 1,10 -diaminodecane as compared to 100 mol-\% selectivity obtained with the reference strain MG1655/pTrc99aald-adh- $t a_{\mathrm{CV}}$ (Figure 4). Since there are multiple metabolic blocks in E. coli YYC202, additional strains were analysed to identify which of the reactions blocked in $E$. coli YYC202 is most important for pyruvate catabolism. It is generally believed that pyruvate dehydrogenase complex (PDHC) is important under aerobic conditions and pyruvate formate lyase (PFL) under anoxic conditions while PoxB might be important during the transition between

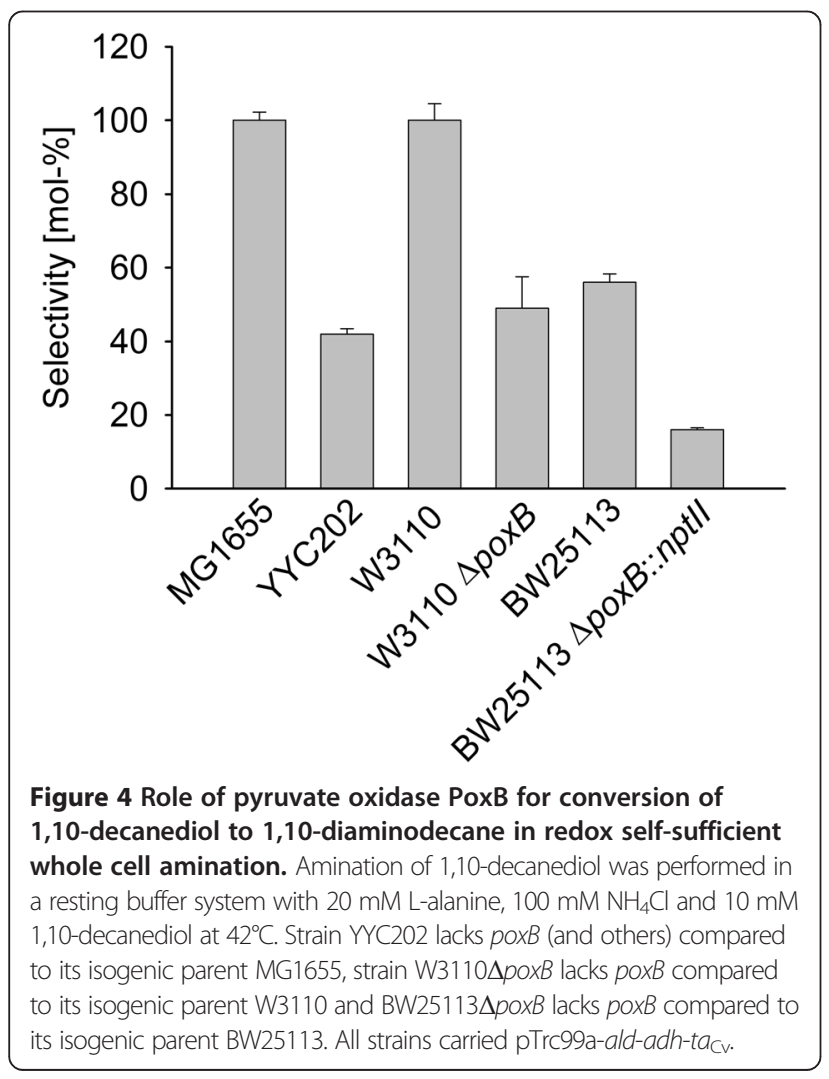

exponential and stationary phase since under microaerobic conditions both PDHC and PFL function poorly [8]. PoxB also contributes to aerobic growth especially at low grow rates [9]. It is known that the pyruvate oxidase gene poxB is induced in the stationary growth phase and this induction is dependent on the alternative sigma factor RpoS [10]. Thus, PoxB might be relevant under the conditions of whole cell biotransformation that are characterized by slow growth and limited oxygen. Therefore, poxB was deleted in E. coli W3110 (s. Materials and method) and the resulting mutant was transformed with pTrc99aald-adh- $t a_{\mathrm{Cv}}$. The whole cell biocatalyst lacking only poxB, W3110 $\Delta$ poxB/pTrc99a-ald-adh-ta $a_{\mathrm{Cv}}$, showed about two-fold reduced amination of 1-10-decanediol to 1,10diaminodecane (Figure 4) indicating that PoxB is the most important enzyme for pyruvate catabolism under the chosen biotransformation conditions. Moreover, since $E$. coli strain differences have been observed to affect biotransformation [11], which may be relevant even between the closely related strains W3110 and MG1655 used here [12], the effect of the lack of PoxB was also analysed in a different strain background, namely BW25113. Indeed, E. coli BW25113/pTrc99a-ald-adh-ta $a_{\mathrm{Cv}}$ converted about three times more (56\%) 1,10-decanediol to 1,10-diaminodecane than its poxB mutant (16\%; Figure 4). Taken together, the addition of $\mathrm{L}$-alanine and its catabolism via pyruvate and pyruvate oxidase PoxB is important for efficient amino functionalization of alcohols by the described whole cell biocatalysts.

\section{Discussion}

Redox self-sufficient amination of alcohols by whole cell biotransformation benefitted from replacing the transaminase from $V$. fluvialis used previously [6] by transaminase $\mathrm{Ta}_{\mathrm{Cv}}$ from C. violaceum [13] since it showed higher activity at $42^{\circ} \mathrm{C}$. Moreover, it showed higher catalytic efficiency with L-alanine as substrate (Table 1). The low activities of transaminases at $42^{\circ} \mathrm{C}$ appeared to be limiting the efficiency of the whole cell biocatalyst since alcohol dehydrogenase of $B$. stearothermophilus and Lalanine dehydrogenase are rather thermostable (Figure 2) $[14,15]$. Indeed, $\mathrm{Ta}_{\mathrm{Cv}}$, which showed higher activity at $42^{\circ} \mathrm{C}$ than $\mathrm{Ta}_{\mathrm{Vf}}$, allowed for efficient conversion of 1,10 decanediol to 1,10 -diaminodecane at $42^{\circ} \mathrm{C}$. Shifting the biotransformation temperature from $37^{\circ} \mathrm{C}$ to $42^{\circ} \mathrm{C}$ led to about three-fold faster conversion employing W3110/ pTrc99a-ald-adh- $t a_{\mathrm{Cv}}$ (Figure 3). Since at $37^{\circ} \mathrm{C}$ both W3110/pTrc99a-ald-adh-ta $a_{\mathrm{Cv}}$ and W3110/pTrc99a-ald$a d h-t a_{\mathrm{Vf}}$ showed comparable production rates, the lower catalytic efficiency of $\mathrm{Ta}_{\mathrm{Vf}}$ did not limit product formation under these conditions.

Addition of L-alanine was required for full and fast conversion of 1,10-decanediol to 1,10-diaminodecane using the whole cell biocatalyst for alcohol amination. The 
consumption of L-alanine over time suggested insufficient L-alanine recycling and loss of pyruvate via the cellular catabolism (Figure 1B; Table 3). This was less pronounced at higher $42^{\circ} \mathrm{C}$ possibly because under these conditions activities of both L-alanine dehydrogenase and alcohol dehydrogenase were increased allowing for more efficient redox cofactor recycling.

L-alanine served two functions in the biotransformation: As substrate in the transaminase reaction and to provide energy and reduction equivalents to the whole cell biocatalyst by catabolism of pyruvate, the co-product of L-alanine-dependent transamination (Figure 1). Under the non-growth conditions of whole cell biotransformation up to $20 \mathrm{mM}$ of alanine were consumed (Table 3 ) with a rate of about $0.04 \mathrm{~g} / \mathrm{g} * \mathrm{~h}$, which is in the same order of magnitude as non-growth maintenance energy $(0.055$ to $0.07 \mathrm{~g}$ of glucose/g*h). Pyruvate addition only partially replaced L-alanine addition since product formation in the presence of $20 \mathrm{mM}$ pyruvate was incomplete (70\%; Table 3). In part, L-alanine was catabolized to acetate. If pyruvate is oxidatively decarboxylated to acetate by pyruvate oxidase PoxB, a reduction equivalent (ubiquinol) is formed which may be used (indirectly) for reductive amination by Lalanine dehydrogenase in the cascade. E. coli is known to produce acetate as overflow metabolite even under fully aerobic conditions, e.g. with excess glucose [16] when $10 \%$ $30 \%$ of carbon flux is directed to acetate formation [17]. Acetate may be formed under aerobic growth conditions by the combined activities of pyruvate dehydrogenase complex PDHC, phosphotransacetylase Pta and acetate kinase AckA (Figure 1B). Besides the reduction equivalent $\mathrm{NADH}$, this pathway yields ATP. A third pathway may be active as a mutant devoid of $p o x B$, pta and ackA still produced acetate [18]. Fast catabolism of glucose to acetate followed by its reuse via acetyl-CoA synthetase (Figure 1B) may be advantageous in comparison to other microorganisms present in its natural habitat that slowly convert the limiting carbon source glucose [9]. In the absence of pyruvate oxidase PoxB conversion of 1,10-decanediol to 1,10diaminodecane was reduced in about the same way as when PoxB and all other known enzymes for pyruvate degradation were missing, thus, indicating that PoxB is the major enzyme for pyruvate degradation under the chosen biotransformation conditions. In the biotransformation described here, the whole cell biocatalysts were harvested in the stationary phase when PoxB dominates.

\section{Conclusions}

The newly derived whole cell biocatalyst W3110/pTrc99aald-adh- $t a_{\mathrm{Cv}}$ allowed for the improvement of redox selfsufficient amination of alcohols displayed by an increase in production rate. This was achieved by replacing the transaminase of $V$. fluvialis by the transaminase of $C$. violaceum, which showed higher activity at $42^{\circ} \mathrm{C}$. The whole cell biocatalyst for redox self-sufficient amination of alcohols required L-alanine in concentrations equimolar to the dialcohol substrate for complete conversion to the diamine. L-alanine catabolism occurred primarily via pyruvate oxidase PoxB under the biotranformation conditions.

\section{Materials and method}

\section{Bacterial strains, plasmids and oligonucleotides}

The E. coli strains, plasmids and oligonucleotides used in this study are listed in Table 4.

Competent cells and vector cloning was performed according to standard DNA work procedure [21]. In this study two different cloning strategies for E. coli expression vectors based on IPTG-inducible pTrc99a were used. Firstly, cut sites were used for inserting a gene into a vector. Therefore, PCR-derived gene product ta of Chromobacterium violaceum [GI: 34105712; codon-optimized] (ta $\mathrm{Cv}_{\mathrm{C}} \mathrm{KpnIRBS \_ for}$; $\mathrm{ta}_{\mathrm{Cv} \_} \mathrm{BamHI}$ _rev) amplified by KOD Hot Start Polymerase Kit (Novagen) was cut with $K p n \mathrm{I}$ and $\mathrm{BamHI}$ and used for ligation with also KpnI and BamHI treated pTrc99A to generate pTrc99a- $t a_{\mathrm{Cv}}$. To construct pTrc99a-ald-adh- $t a_{\mathrm{Cv}}$ the $B a m H I$ cut site was inserted upstream of $t a_{\mathrm{Vf}}$ within the artificial operon ald-adh-ta $a_{\mathrm{Vf}}$ of $\mathrm{pTrc} 99 \mathrm{a}-$ ald-adh-ta $a_{\mathrm{Vf}}$ by site directed mutagenesis using the oligonucleotides pTrc99a-ald-adh-ta ${ }_{\text {Vf_ }}$ mut_for [22]. The newly derived vector pTrc99a-ald-adh-tavf_mut was then cut by BamHI and ligated with BamHI cut ta of Chromobacterium violaceum that was amplified by KOD Hot Start Polymerase Kit (Novagen, pTrc99a-ald-adh-ta ${ }_{\mathrm{Cv}}$ for, pTrc99a-aldadh-ta $\mathrm{Cv}_{-}$rev). Secondly, to construct pTrc99A-ta $a_{\mathrm{Vf}}$ the gene ta of Vibrio fluvialis was amplified with the oligonucleotides tavf_RBS_for and tavf_rev and assembled with EcoICRI restricted pTrc99a using Gibson assembly method [23]. Then, E. coli DH5 $\alpha$ was transformed with the ligation products. $\mathrm{CaCl}_{2}$-competent $E$. coli $\mathrm{DH} 5 \alpha$ were heat-shocked for the uptake of ligation products. Newly derived vectors were proven by sequencing and $E$. coli W3110 was transformed with correct plasmids pTrc99a$t a_{\mathrm{Vf}}, \mathrm{p} \operatorname{Trc} 99 \mathrm{a}-\mathrm{t} a_{\mathrm{CV}}$ and $\mathrm{p} T \mathrm{rc} 99 \mathrm{~A}-a l d-a d h-t a_{\mathrm{CV}}$ and $E$. coli MG1655 as well as E. coli YCC202 with pTrc99A-ald$a d h-t a_{\mathrm{Cv}}$.

\section{Cultivation conditions and media}

Standard cultivation of $E$. coli was performed in LuriaBertani medium (LB-medium: $10 \mathrm{~g} / \mathrm{L} \mathrm{NaCl}, 10 \mathrm{~g} / \mathrm{L}$ tryptone, $5 \mathrm{~g} / \mathrm{L}$ yeast extract) at $37^{\circ} \mathrm{C}$ and $200 \mathrm{rpm}$ in baffled flasks or plated on LB-Agar as it is not declared otherwise. When strains harboring plasmid pTrc99A and its derivatives, $100 \mu \mathrm{g} / \mathrm{mL}$ ampicillin was supplemented to the medium. Strain YYC202 and its derivatives were supplemented with $25 \mu \mathrm{g} / \mathrm{ml}$ streptomycin and $10 \mu \mathrm{g} / \mathrm{ml}$ tetracycline, additionally. 
Table 4 Strains, plasmids and oligonucleotides used in this study

\begin{tabular}{|c|c|c|}
\hline Strains & Relevant characteristics & Reference \\
\hline \multirow[t]{2}{*}{ E. coli $\mathrm{DH} 5 \mathrm{a}$} & $\mathrm{F}^{-}$thi-1 endA1 hsdr17(r- $\left.\mathrm{r}^{-}, \mathrm{m}^{-}\right)$supE44 $\Delta$ lacU169 & [19] \\
\hline & ( $\phi 80 / a c Z \Delta M 15)$ recA1 gyrA96 relA1 & \\
\hline E. coli W3110 & $\mathrm{F}^{-} \lambda^{-} \mathrm{INV}(r r n \mathrm{D}-r r n \mathrm{E}) 1$ & [19] \\
\hline E. coli MG1655 & $F^{-} \lambda^{-} i l v G-r f b-50 r p h-1$ & [19] \\
\hline E. coli YYC202 & $\Delta a c e E F$ pfl1 poxB1 pps4 rpsL zbi::Tn10 & [8] \\
\hline E. coli BW25113 & 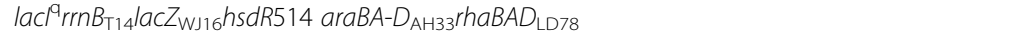 & {$[20]$} \\
\hline W3110/pTrc99A-ald-adh-tavf & E. coli W3110 harboring pTrc99A-ald-adh-ta with the transaminase of Vibrio fluvialis & [6] \\
\hline W3110/pTrc99A-ald-adh-ta $a_{C v}$ & $\begin{array}{l}\text { E. coli W3110 harboring pTrc99A-ald-adh-ta with the transaminase of Chromobacterium } \\
\text { violaceum }\end{array}$ & This study \\
\hline MG1655/pTrc99A-ald-adh-ta ${ }_{\mathrm{Cv}}$ & $\begin{array}{l}\text { E. coli MG1655 harboring pTrc99A-ald-adh-ta with the transaminase of Chromobacterium } \\
\text { violaceum }\end{array}$ & This study \\
\hline YCC202/pTrc99A-ald-adh-ta $a_{\mathrm{CV}}$ & $\begin{array}{l}\text { E. coli YCC202 harboring pTrc99A-ald-adh-ta with the transaminase of Chromobacterium } \\
\text { violaceum }\end{array}$ & This study \\
\hline BW25113/pTrc99A-ald-adh-tacr & $\begin{array}{l}\text { E. coli BW25113 harboring pTrc99A-ald-adh-ta with the transaminase of Chromobacterium } \\
\text { violaceum }\end{array}$ & This study \\
\hline $\begin{array}{l}\text { JW0855-1/pTrc99A-ald-adh-ta } \\
\text { (BW25113 } 2 \text { poxB::kan) }\end{array}$ & $\begin{array}{l}\text { F-, } \Delta\left(\text { araD-araB) } 567, \Delta / a c Z 4787(:: r r n B-3), \lambda^{-}, \Delta p o x B 772:: k a n, r p h-1, \Delta(\text { rhaD-rhaB) } 568, \text { hsdR514; }\right. \\
\text { harboring the plasmid pTrc99A-ald-adh-ta with the transaminase of Chromobacterium } \\
\text { violaceum }\end{array}$ & $\begin{array}{l}{[20] / \text { Transformation }} \\
\text { in this study }\end{array}$ \\
\hline 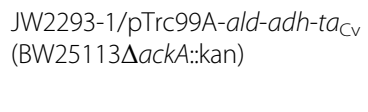 & $\begin{array}{l}\text { F-, } \Delta\left(\text { araD-araB) } 567, \Delta / a c Z 4787(:: r r n B-3), \lambda^{-}, \Delta a c k A 778:: k a n, r p h-1, \Delta(\text { rhaD-rhaB) } 568, \text { hsdR514; }\right. \\
\text { harboring the plasmid pTrc99A-ald-adh-ta with the transaminase of Chromobacterium } \\
\text { violaceum }\end{array}$ & $\begin{array}{l}{[20] / \text { Transformation }} \\
\text { in this study }\end{array}$ \\
\hline $\begin{array}{l}\text { JW2294-1/pTrc99A-ald-adh-tacr } \\
\text { (BW25113 pta:kan) }\end{array}$ & 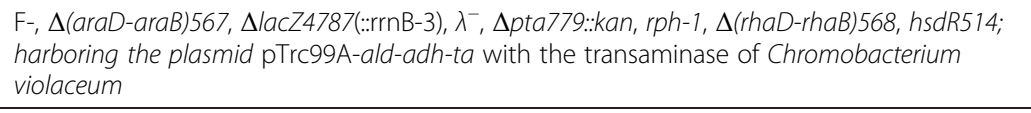 & $\begin{array}{l}{[20] / \text { Transformation }} \\
\text { in this study }\end{array}$ \\
\hline Plasmids & Relevant characteristics & Reference \\
\hline pTrc99A-tavf & pTrc99A carrying ta of Vibrio fluvialis & This study \\
\hline$p \operatorname{Trc99A-ta_{CV}}$ & pTrc99A carrying ta of Chromobacterium fluvialis & This study \\
\hline \multirow[t]{4}{*}{ pTrc99A-ald-adh-tavf } & pTrc99A carrying ald-adh-tavf synthetic operon & [6] \\
\hline & ald from B. subtilis 168 & \\
\hline & adh from B. stearothermophilus & \\
\hline & ta from $V$. fluvialis & \\
\hline pTrc99A-ald-adh-tavf_mut & pTrc99A-ald-adh-ta $a_{\mathrm{vf}}$ with BamHI cut site upstream of $t a_{\mathrm{Vf}}$ & This study \\
\hline \multirow[t]{4}{*}{ pTrc99A-ald-adh-ta $a_{\mathrm{Cv}}$} & pTrc99A carrying ald-adh-ta $a_{\mathrm{Cv}}$ synthetic operon & This study \\
\hline & ald from B. subtilis 168 & \\
\hline & adh from B. stearothermophilus & \\
\hline & ta from C. violaceum & \\
\hline Oligonucleotides & Sequence $5^{\prime} \rightarrow 3^{\prime}$ & Use \\
\hline tavf_RBS_for & CAGACCATGGAATTCGAGCAGGAAACAGACCATGAACAAACCGCAGAGCTG & pTrc99A-tavf \\
\hline tavf_rev & ATCCCCGGGTACCGAGTTACGCAACTTCCGCGAAAAC & pTrc99A-tavf \\
\hline 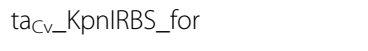 & CAAGGTACCCAGGAAACAGACCATGCAGAAACAGCGTACCACC & pTrc99A-ta $a_{C v}$ \\
\hline tacv_BamHI_rev & GTTGGATCCTTAGGCCAGACCACGTGCTTTC & pTrc99A-tacr \\
\hline pTrc99a-ald-adh-tavf_mut_for & GGAAGATAAATAAGGATCCCAGGAAACAGACCATGAAC & pTrc99A-ald-adh-tacv \\
\hline pTrc99a-ald-adh-tavf_mut_rev & CTGGGATCCTTATTTATCTTCCAGGGTCAGAACAACA & pTrc99A-ald-adh-tacr \\
\hline pTrc99a-ald-adh-tacv_for & CAAGGATCCCAGGAAACAGACCATGCAGAAACAGCGTACCACC & pTrc99A-ald-adh-tacv \\
\hline pTrc99a-ald-adh-tacv_rev & GTTGGATCCTTAGGCCAGACCACGTGCTT & pTrc99A-ald-adh-tacv \\
\hline
\end{tabular}




\section{Preparation of cell free extract and enzyme assay}

The E. coli derivatives were grown in $\mathrm{LB}+100 \mu \mathrm{g} / \mathrm{mL}$ ampicillin until an optical density at $600 \mathrm{~nm}$ of $0.6-0.8$, induced with $1 \mathrm{mM}$ isopropyl- $\beta$-D-thiogalactopyranosid (IPTG) and harvested in the exponential phase at $\mathrm{OD}_{600}=$ 3.5. $10 \mathrm{~mL}$ of the cell culture was harvested and always kept on ice. The cells were once washed with buffer for the enzyme assay, resuspended in $1 \mathrm{~mL}$ of the same buffer and then lysed by sonication (Ultrasonic processor UP200S, Hielscher Ultrasound Technology, Teltow, Germany) for 2 minutes (cycle 0.5; amplitude 55\%). Cell cebris was centrifuged at $10.000 \mathrm{x}$ g at $4^{\circ} \mathrm{C}$ for 1 hour and clear cell extract was used for the measurement of the enzyme activity.

\section{Measurement of alanine dehydrogenase activity}

$50 \mathrm{mM} \mathrm{Na} \mathrm{CO}_{3} \mathrm{pH} 10$ was used for cell washing. For measuring the activity of alanine dehydrogenase pyruvate was converted to L-alanine by $\mathrm{NADH}$ consumption spectrophotometrically at $340 \mathrm{~nm}$. Therefore, $50 \mathrm{mM}$ $\mathrm{Na}_{2} \mathrm{CO}_{3} \mathrm{pH} 8.5,50 \mathrm{mM} \mathrm{NH}{ }_{4} \mathrm{Cl}, 10 \mathrm{mM}$ pyruvate and $0.25 \mathrm{mM} \mathrm{NADH}$ where mixed in a cuvette, filled up to

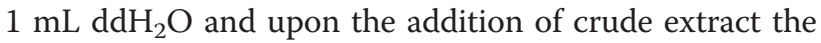
reductive amination was initiated and measured for $3 \mathrm{mi}$ nutes. The assay was performed in triplicates and one enzyme unit was calculated to be the amount of enzyme that catalyzes the conversion of $1 \mu \mathrm{mol}$ substrate in $1 \mathrm{~min}$.

\section{Measurement of alcohol dehydrogenase activity}

$25 \mathrm{mM}$ Sodium phosphate buffer $\mathrm{pH} 8$ was used for cell washing. For measuring the alcohol dehydrogenase activity 1,4-butanediol was oxidized to hydroxybutyraldehyde and $\mathrm{NADH}$ formation followed spectrophotometrically at $340 \mathrm{~nm}$. Therefore, $25 \mathrm{mM}$ Na-P-buffer pH 8, $18 \mathrm{mM} \mathrm{1,4}$ butanediol and $10 \mathrm{mM} \mathrm{NAD}^{+}$were mixed in a cuvette, filled up to $1 \mathrm{~mL} \mathrm{ddH}_{2} \mathrm{O}$ and reaction was initiated upon the addition of crude extract (triplicates). The NADH formation was followed over 3 minutes and one enzyme unit was calculated to be the amount of enzyme that catalyzes the conversion of $1 \mu \mathrm{mol}$ substrate in $1 \mathrm{~min}$. To analyze substrate specificity to 1-hexanol, 1-octanol, 1,6-hexanediol, 1,8-hexanediol, cyclohexanol, benzylalcohol and 2hexanol same conditions were used but different substrate concentration were added to estimate $K_{m}$ and $V_{\text {max }}$-values via Lineweaver-Burk Plot.

\section{Measurement of transaminase activity}

$100 \mathrm{mM}$ Potassium-phosphate buffer $\mathrm{pH} 7.4$ was used for cell washing. Reaction conditions were: $100 \mathrm{mM} \mathrm{K}$ P-buffer $\mathrm{pH}$ 7.4, $50 \mathrm{mM}(\mathrm{S})-\alpha-\mathrm{MBA}$ and $10 \mathrm{mM}$ pyruvate. The transamination was initiated upon the addition of crude extract and samples were taken continuously. The reaction was stopped with $75 \mu \mathrm{l} 16 \%$ perchloracetic acid. The samples where neutralized by the addition of
$40 \mu$ buffer containing $20 \mathrm{mM}$ Tris/ $\mathrm{HCl} \mathrm{pH} 8$ and $23 \mathrm{mM} \mathrm{K} \mathrm{CO}_{3}$. L-alanine formation was measured via HPLC and one enzyme unit was calculated to be the amount of enzyme to catalyze the formation of $1 \mu \mathrm{mol}$ product in $1 \mathrm{~min}$.

The experimental procedure for the estimation of catalytic efficiency was equal but hexanal was used as substrate instead of $(\mathrm{S})-\alpha-\mathrm{MBA}$. The Reaction conditions were: $100 \mathrm{mM}$ K-P-buffer pH 7.4, $10 \mathrm{mM}$ hexanal and varying concentrations of L-alanine. Hexylamine formation was measured via HPLC and one enzyme unit was calculated to be the amount of enzyme to catalyze the formation of $1 \mu \mathrm{mol}$ product in $1 \mathrm{~min}$.

\section{Whole cell biotransformation with resting cells}

E. coli W3110/pTrc99A and its derivatives W3110/ pTrc99A-ald-adh-ta and W3110/pTrc99A-ta-ald-adh were inoculated to an initial $\mathrm{OD}_{600}=0.1$ in LB-medium plus $20 \mathrm{mM}$ Mops and $100 \mu \mathrm{g} / \mathrm{mL}$ ampicillin and incubated at $37^{\circ} \mathrm{C}$ and $200 \mathrm{rpm}$. At an $\mathrm{OD}_{600}=0.6-0.81 \mathrm{mM}$ IPTG was added to the expression culture to induce the cells and cultivation was continued as described above. 15 hours cells were harvested for a final $\mathrm{OD}_{600}=10$ in $20 \mathrm{~mL}$ final volume, once washed with $50 \mathrm{mM}$ Hepes buffer $\mathrm{pH} 7$ and prepared for whole cell biotransformation in a resting buffer system with the mentioned buffer. $\mathrm{NH}_{4} \mathrm{Cl}$ and L-alanine were added to the system when necessary and concentrations are given in the text. The test reaction containers (100 mL Schottbottle) where incubated at $37^{\circ} \mathrm{C}$ or $42^{\circ} \mathrm{C}$ and $200 \mathrm{rpm}$ and samples for HPLC-analytics were taken in intervals throughout the production.

\section{HPLC-analysis}

Extracellular amines and 1-amino-10-decanol were analyzed by high-pressure liquid chromatography (HPLC, 1200 series, Agilent Technologies Deutschland $\mathrm{GmbH}$, Böblingen, Germany). Samples were centrifuged at $10.000 \times$ $\mathrm{g}$ for 5 minutes and the clear supernatant was taken for HPLC-measurement. For the detection samples were derivatized with ortho-phthaldialdehyde (OPA) automatically before entering the precolumn (LiChrospher 100 RP8 EC-5 $\mu, 40 \times 4.6$ mm, CS-Chromatographie Service $\mathrm{GmbH}$, Langerwehe, Germany) and the main column (LiChrospher 100 RP8 EC-5 $\mu, 125 \times 4.6$ mm, Langerwehe, Germany) for separation. The used mobile phase was made of A: $0.25 \%(\mathrm{v} / \mathrm{v}) \mathrm{Na}$-acetate buffer $\mathrm{pH} 6$ and B: Methanol; 0 min 30\% B, 1 min 30\% B, 8 min 70\% B, 13 min 90\% B, $16 \min 70 \%$ B, 18 min $30 \%$ B. 1,7-diaminoheptane was used as internal standard.

The detection of amino acids were performed with a quicker HPLC-method but derivatization with OPA was used equally to amine detection. Here, through a precolumn (LiChrospher $100 \mathrm{RP} 18-5 \mathrm{EC} ; 40 \times 4 \mathrm{~mm}$ ) and the main column (LiChrospher 100 RP18 EC-5 $\mu$; $125 \times$ 
$4.6 \mathrm{~mm}$; CS-Chromatographie Service $\mathrm{GmbH}$, Langerwehe, Germany) amino acids were separated and detected by a FLD-detector. As an internal standard L-asparagine was used and the gradient for improved separation was made of A: $100 \mathrm{mM}$ Sodiumacetate pH 7.2 and B: Methanol; $0 \min 25 \%$ B, $0.5 \min 45 \%$ B, $4 \min 65 \%$ B, 7 min $70 \%$ B, 7.2 min $80 \%$ B, 7.4 min $85 \%$ B, 8 min $20 \%$ B, 10.6 min $20 \% \mathrm{~B}$.

Overflow metabolites were separated by the Organic Acid Resin column $(800 \times 8 \mathrm{~mm})$ from CS-Chromatographie Service $\mathrm{GmbH}$ (Langerwehe, Germany) and detected with DAD-detector. An isocratic elution with $5 \mathrm{mM} \mathrm{H}_{2} \mathrm{SO}_{4}$ and a flow rate of $0.7 \mathrm{ml} / \mathrm{min}$ for the separation of the samples.

\section{Competing interests}

The authors declare that they have no competing interests.

\section{Authors' contribution}

VFW and SK designed the experiments. SK conducted the experiments, analyzed the results and wrote the manuscript. VFW reviewed and revised the manuscript. Both authors read and approved the final manuscript.

\section{Acknowledgement}

We would like to acknowledge Drs. Philip Engels, Jan Pfeffer and Thomas Haas (Evonik Industries AG) and Prof. Dr. Kroutil (University Graz) for provision of strains and plasmids and their collaboration within the BMBF-cofunded Biolndustrie 2021 project "Biooxidations- und Aminierungstechnologie als Plattform für funktionelle Amine als Monomerbausteine". We acknowledge support of the publication fee by Deutsche Forschungsgemeinschaft and the Open Access Publication Funds of Bielefeld University.

Received: 5 September 2014 Accepted: 30 December 2014

Published online: 23 January 2015

\section{References}

1. Liu W, Peterson PE, Carter RJ, Zhou X, Langston JA, Fisher AJ, et al. Crystal structures of unbound and aminooxyacetate-bound Escherichia coli gamma-aminobutyrate aminotransferase. Biochemistry-Us. 2004;43:10896-905.

2. Lyskowski A, Gruber C, Steinkellner G, Schurmann M, Schwab H, Gruber K, et al. Crystal structure of an (R)-selective omega-transaminase from Aspergillus terreus. PLoS One. 2014;9(1):e87350. doi:10.1371/journal.pone.0087350.

3. Wichmann R, Vasic-Racki D. Cofactor regeneration at the lab scale. Adv Biochem Eng Biotechnol. 2005;92:225-60.

4. Lorenz E, Klatte S, Wendisch VF. Reductive amination by recombinant Escherichia coli: whole cell biotransformation of 2-keto-3-methylvalerate to L-isoleucine. J Biotechnol. 2013;168:289-94.

5. Sattler JH, Fuchs M, Tauber K, Mutti FG, Faber K, Pfeffer J, et al. Redox self-sufficient biocatalyst network for the amination of primary alcohols. Angew Chem Int Edit. 2012;51:9156-9.

6. Klatte $S$, Wendisch VF. Redox self-sufficient whole cell biotransformation for amination of alcohols. Bioorg Med Chem. 2014;22:5578-85.

7. TZB Gerharz, Takors R, Bott M. Produktion von Pyruvat aus Glucose mit Escherichia coli. Biospektrum. 2001:29-33

8. Chang YY, Wang AY, Cronan JE. Expression of Escherichia coli pyruvate oxidase (PoxB) depends on the sigma-factor encoded by the rpoS(katf) gene. Mol Microbiol. 1994;11:1019-28.

9. Abdel-Hamid AM, Attwood MM, Guest JR. Pyruvate oxidase contributes to the aerobic growth efficiency of Escherichia coli. Microbiol-Sgm. 2001;147:1483-98.

10. Weber H, Polen T, Heuveling J, Wendisch VF, Hengge R. Genome-wide analysis of the general stress response network in Escherichia coli: sigma(S)-dependent genes, promoters, and sigma factor selectivity. J Bacteriol. 2005;187:1591-603.

11. Kuhn D, Fritzsch FSO, Zhang XM, Wendisch VF, Blank LM, Buhler B, et al. Subtoxic product levels limit the epoxidation capacity of recombinant $E$. coli by increasing microbial energy demands. J Biotechnol. 2013;163:194-203.
12. Vijayendran C, Polen T, Wendisch VF, Friehs K, Niehaus K, Flaschel E. The plasticity of global proteome and genome expression analyzed in closely related W3110 and MG1655 strains of a well-studied model organism, Escherichia coli-K12. J Biotechnol. 2007;128:747-61.

13. Kaulmann U, Smithies K, Smith MEB, HaileS HC, Ward JM. Substrate spectrum of omega-transaminase from Chromobacterium violaceum DSM30191 and its potential for biocatalysis. Enzyme Microb Tech. 2007:41:628-37.

14. Fiorentino G, Cannio R, Rossi M, Bartolucci S. Decreasing the stability and changing the substrate specificity of the Bacillus stearothermophilus alcohol dehydrogenase by single amino acid replacements. Protein Eng. 1998;11:925-30.

15. Shin JS, Yun H, Jang JW, Park I, Kim BG. Purification, characterization, and molecular cloning of a novel amine : pyruvate transaminase from Vibrio fluvialis JS17. Appl Microbiol Biot. 2003:61:463-71.

16. Veit A, Polen T, Wendisch VF. Global gene expression analysis of glucose overflow metabolism in Escherichia coli and reduction of aerobic acetate formation. Appl Microbiol Biotechnol. 2007;74:406-21.

17. Farmer WR, Liao JC. Reduction of aerobic acetate production by Escherichia coli. Appl Environ Microb. 1997;63:3205-10.

18. Phue JN, Lee SJ, Kaufman JB, Negrete A, Shiloach J. Acetate accumulation through alternative metabolic pathways in ackA(-) pta(-) poxB(-) triple mutant in E. coli B (BL21). Biotechnol Lett. 2010;32:1897-903.

19. Sambrook J, Russell D. Molecular Cloning. A Laboratory Manual. 3rd ed. Cold Spring Harbor, NY: Cold Spring Harbor Laboratoy Press; 2001.

20. Baba T, Ara T, Hasegawa M, Takai Y, Okumura Y, Baba M, et al. Construction of Escherichia coli K-12 in-frame, single-gene knockout mutants: the Keio collection. Mol Syst Biol. 2006;2:2006 0008 .

21. Hanahan D. Studies on transformation of Escherichia coli with plasmids. J Mol Biol. 1983;166:557-80.

22. Liu HT, Naismith JH. An efficient one-step site-directed deletion, insertion, single and multiple-site plasmid mutagenesis protocol. BMC Biotechnology. 2008:8:91. doi:10.1186/1472-6750-8-91.

23. Gibson DG, Young L, Chuang RY, Venter JC, Hutchison CA, Smith HO. Enzymatic assembly of DNA molecules up to several hundred kilobases. Nat Methods. 2009;6:343-1.

\section{Submit your next manuscript to BioMed Central and take full advantage of:}

- Convenient online submission

- Thorough peer review

- No space constraints or color figure charges

- Immediate publication on acceptance

- Inclusion in PubMed, CAS, Scopus and Google Scholar

- Research which is freely available for redistribution 